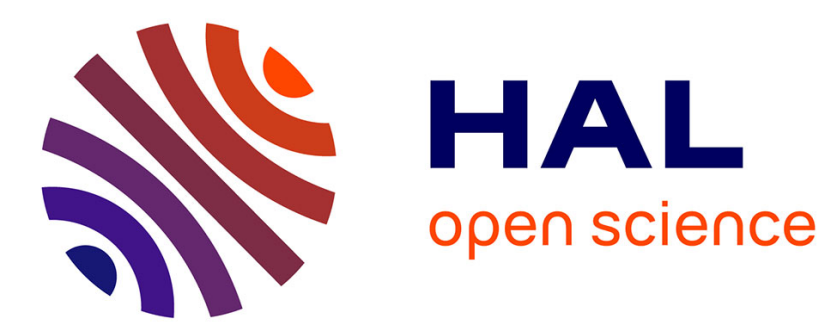

\title{
Energetic performances of a refrigerating loop using ice slurry
}

\author{
Ikram El Abbassi, Jean Castaing-Lasvignottes, Jean-Pierre Bedecarrats, \\ Jean-Pierre Dumas, Et Abdelaziz Mimet
}

\section{To cite this version:}

Ikram El Abbassi, Jean Castaing-Lasvignottes, Jean-Pierre Bedecarrats, Jean-Pierre Dumas, Et Abdelaziz Mimet. Energetic performances of a refrigerating loop using ice slurry. Applied Thermal Engineering, 2010, 30 (8-9), pp.962. 10.1016/j.applthermaleng.2010.01.006 . hal-00621288

\section{HAL Id: hal-00621288 \\ https://hal.science/hal-00621288}

Submitted on 10 Sep 2011

HAL is a multi-disciplinary open access archive for the deposit and dissemination of scientific research documents, whether they are published or not. The documents may come from teaching and research institutions in France or abroad, or from public or private research centers.
L'archive ouverte pluridisciplinaire HAL, est destinée au dépôt et à la diffusion de documents scientifiques de niveau recherche, publiés ou non, émanant des établissements d'enseignement et de recherche français ou étrangers, des laboratoires publics ou privés. 


\section{Accepted Manuscript}

Energetic performances of a refrigerating loop using ice slurry

Ikram El Abbassi, Jean Castaing-Lasvignottes, Jean-Pierre Bédécarrats, JeanPierre Dumas, et Abdelaziz Mimet

PII:

S1359-4311(10)00012-8

DOI:

10.1016/j.applthermaleng.2010.01.006

Reference:

ATE 2966

To appear in:

Applied Thermal Engineering

\section{APPLIED}

THERMAL

ENGINEERING

Received Date: $\quad 29$ June 2009

Accepted Date: $\quad 7$ January 2010

Please cite this article as: I.E. Abbassi, J. Castaing-Lasvignottes, J-P. Bédécarrats, J-P. Dumas, e.A. Mimet, Energetic performances of a refrigerating loop using ice slurry, Applied Thermal Engineering (2010), doi: 10.1016/ j.applthermaleng.2010.01.006

This is a PDF file of an unedited manuscript that has been accepted for publication. As a service to our customers we are providing this early version of the manuscript. The manuscript will undergo copyediting, typesetting, and review of the resulting proof before it is published in its final form. Please note that during the production process errors may be discovered which could affect the content, and all legal disclaimers that apply to the journal pertain. 


\section{Energetic performances of a refrigerating loop using ice slurry}

Ikram El Abbassi ${ }^{1,2}$, Jean Castaing-Lasvignottes ${ }^{1 *}$, Jean-Pierre Bédécarrats ${ }^{1}$, Jean-Pierre Dumas ${ }^{1}$ et Abdelaziz Mimet ${ }^{2}$

${ }^{1}$ Laboratoire de Thermique, Energétique et Procédés (LaTEP), Université de Pau et des Pays de l'Adour (UPPA), BP 1155 - 64013 Pau, France.

2 Laboratoire d'Energétique et Mécanique des Fluides et Sciences des matériaux,

Faculté des Sciences, BP 2121, 93000 Tétouan, Maroc.

*corresponding author:

jean.castaing@univ-pau.fr, Tel :0033559407439, Fax :0033559407435

\section{Abstract}

The consideration of environmental constraints in production, transport and distribution of cold energy resulted in reconsidering the practices of installations dimensioning in particular. Their containment led to the development of secondary refrigerants such as ice slurries to store, transport and distribute the cold energy. These heat transfer fluids should have good thermophysical properties, giving high transport capability, high heat transfer ability as well as low pressure drops. The use of ice slurries can lead to lower flow rates and smaller pumping power compared to single phase fluid. The purpose of the presented work is to study the distribution network of indirect cold systems thanks to a model allowing the evaluation of the influence of various parameters on the operating behaviour of the installation. The available domain for the use of secondary heat transfer fluid (whether in their single phase or two phase

form) is determined considering the best design from an energetic point of view. Because of the essential role of the fluid distribution between the production site and consumers, we focus our study on pressure drops and pumping power due to the fluid flow in cooling loops. For each investigated case, the minimum consumption power is obtained with the two phases (solidliquid) heat transfer fluid (ice slurry). 
Keywords: secondary heat transfer fluid, monophasic, ice slurry, pressure drop, pumping power, modelling.

\section{Introduction}

During the last decade, some refrigerants have been identified as ozone depleting and/or greenhouse substances. So, industrial and commercial sectors have been working to find alternative refrigerants having both good physical and thermodynamic characteristics as well as less adverse effects on the environment. In the same time, work has been done to reduce the amount of refrigerant in installations by the use of secondary refrigeration loops. The heat transfer fluid in those loops is very often water or an aqueous solution. These systems usually use single phase heat transfer fluids but it is possible to improve their efficiencies by using diphasic secondary refrigerants such as ice slurries. Ice slurry is a mixture of an aqueous solution and fine ice crystals. This promising technology has main advantages in particular thanks to the latent heat of ice: a more efficient heat transfer fluid, better temperature stabilization and higher power [1].

These features have made ice slurries a competitive alternative to conventional secondary refrigeration systems [2]. For example, it has been successfully employed in many applications from comfort cooling and commercial refrigeration to industrial production processes [3]. However, more engineering information is required on fluid flow and heat transfer characteristics as well as on a reliable, energy efficient and cost effective production of the ice, for ice slurries to become more widely accepted The transport properties of ice slurry have been studied extensively. Most previous studies focussed on the heat transfer and pressure drops [4].

Niezgoda-Zelasko [5], Niezgoda-Zelasko and Zalewski [6] and recently, Grozdek et al., $[7,8]$ present results of studies on pressure drops and heat transfers in ice slurry flows 
through horizontal tubes. The secondary fluid was prepared by mixing ethanol and water to obtain an initial alcohol concentration of about $10 \%$. Generally, with higher ice mass fraction and velocity, they found that the heat transfer is enhanced and the pressure drop is high in comparison to the single phase flow. Up to ice mass fraction between $10 \%$ and $15 \%$ the mean heat transfer coefficient shows only slight (laminar regime) or no increase (turbulent regime) in comparison to single phase flow. Beyond that ice mass fraction, the heat transfer coefficient is increased significantly. The same evolution was found for pressure drops. However for ice concentrations of $15 \%$ and higher, certain velocity exists at which the ice slurry pressure drop is lower than for single phase flow (transition zone from turbulent to laminar).

Bedecarrats et al [9] studied the behaviour in heat exchangers of ice slurry composed of fine ice particles inside an ethanol-water solution. The heat transfer and friction characteristics were studied in two double pipe heat exchangers, one with a smooth surface and another with an improved surface. Heat transfer coefficients and pressure drops were experimentally investigated for the slurry flowing in the internal tube with ice mass fractions ranging from $0 \%$ to $30 \%$ and with flow velocities between 0.3 and $1.9 \mathrm{~m} \mathrm{~s}^{-1}$. For some flow velocities, the results showed that an increase in the ice fractions caused a change in the slurry flow structure influencing the evolution of the pressure drops and of the heat transfer coefficients. Critical ice fraction values were determined corresponding to a change flow structure from laminar to turbulent motion revealed by the evolution of the friction factor.

However, very little work has been conducted on the flow of slurries through industrial heat exchangers. Norgaard et al. [10] studied the behaviour of ice slurry in a piping system, including pumps, plate heat exchangers and various types of fittings. They found that the pump performance decreases with increasing ice concentration due to the 
increasing viscosity of the ice slurry and the additional effect of the ice particles. For a standard plate heat exchanger, results indicated an increase in the overall heat transfer coefficient and pressure drop with increasing ice fraction. Pressure loss coefficients in selected fittings have been measured to reveal the dependency of ice concentration. Jensen et al. [11] reported on heat transfer coefficients and pressure drops performed on three pipes measuring 12,16 and $20 \mathrm{~mm}$ in diameter. The ice slurry mixture was based on $10 \%$ ethanol aqueous solution with an ice fraction of 0 to 0.30 and with a particle size of less than $0.2 \mathrm{~mm}$. The velocity in the pipes was $0.5,1.0$ and $1.5 \mathrm{~m} / \mathrm{s}$. They report that the heat transfer coefficient increased with increasing ice fraction and velocity. For the hydraulic performance, they found no change in pressure drops with varying ice fraction as long as the ice fraction was lower than 0.1-0.15 and an increase beyond. Bellas et al. [12] performed measurements on ice slurry (based on 5\% propylene glycol aqueous solution) in a plate heat exchanger with an ice mass fraction between 0 and 0.25. The flow rate was between 1.0 and $3.7 \mathrm{~m}^{3} \mathrm{~h}^{-1}$. By increasing the ice mass fraction from 0 to 0.20 the pressure drop increased by around $15 \%$ over the flow range. The overall heat transfer coefficient of the plate heat exchanger increased significantly with increasing flow rate. The variation of ice fraction did not appear to have any effect on the overall heat transfer coefficient.

Shire et al. [13] conducted experiments to determine the characteristics of ice flows through industrial heat exchangers (plate heat exchanger and tubular heat exchanger) to extend the range of previous work to higher ice fractions. As expected from most previous research, the pressure drops experienced were greater than those with water, and rose with increasing ice fraction and flow rate.

The heat transfer and pressure drop results obtained by the different investigators indicate that the behaviour of ice slurries is a function of a number of parameters which 
include the mixture viscosity, the Reynolds number and the ice fraction. These parameters have an influence on the energy consumption in installation using secondary refrigeration loops.

There have few publications on the subject about the energetic advantages and the investments of installations using ice slurry. Haberschill et al. [14] have compared the use of ice slurry (water + ethanol) and chilled water in the case of air conditioning in a building. The result of this work is not favourable to ice slurry. This conclusion is explained by a high level of the temperature needed in the case of the air conditioning. The main objective of our investigation is to verify the interest of the use of ice slurry for cooling systems.

Our goal in this work is to determine the available domain for the use of secondary heat transfer fluid (whether in their single phase or two phases form) and to find out the best design from an energetic point of view. Considering such an objective, researchers as well as engineers have to solve the problem consisting in distributing the maximum amount of heat with the lowest amount of energy needed to transport the fluid. As in other hydraulic energy transport systems, pumps are essential to distribute the fluid between the production site and consumers. So we will focus our study on pressure drops and pumping power due to the flow of a water/ethanol mixture in cooling loops. Firstly, the studied installation and all considered assumptions of this investigation are described. Then, the used methodology is explained, in particular, to calculate the pressure drops (frictional losses in straight pipes and losses due to various fittings) created respectively in the two branches of the loop and in the industrial heat exchangers.

Finally, we present results obtained by the model developed in this work which enabled to evaluate the pumping power. 


\section{Model description}

\subsection{System description}

As already mentioned we will focus our study on pressure drops and pumping power due to the fluid flow in cooling loops.

The investigated process that has been considered and that has been studied, has to exchange an amount of power $\dot{Q}_{a p p}$, at a fixed temperature $T_{a p p}$ (figure 1). The secondary heat transfer fluid is cooled in the evaporator of a vapour compression refrigeration machine.

The investigated case considers the pump and two exchangers; one receiving the cold production from the evaporator, the other one receiving the amount of heat of the application corresponding to the refrigeration loads. This latter is given by the expression:

$\dot{Q}_{a p p}=\dot{m}_{f} \cdot\left(h_{f, o u t}-h_{f, \text { in }}\right)$

where $m_{f}$ represents the mass flow rate of the heat transfer fluid and $h_{f}$, its enthalpy, at the input and at the output of the heat exchanger.

Both sensible heat and latent heat of melting are included in the enthalpy expression, the thermophysical properties are taken from Ben Lakhdar'work [15].

As a first hypothesis, we have considered a pinch of $5^{\circ} \mathrm{C}$ between the application temperature $T_{a p p}$ and the outlet of the secondary heat transfer fluid $T_{\text {out }}$. Thus, for a given mass flow rate, the temperature $T_{\text {in }}$ at the inlet of the heat exchanger is deduced from this energy balance by an iterative calculation due to the temperature and ice fraction dependence of the enthalpy.

\subsection{Transport properties and energetic aspects}


The major pressure drops of the secondary heat transfer loop have two origins:

- The first one concerns the distribution network itself (i.e. the tubes). The loads (also called application power) is one of the parameters of the model and varies quite significantly, the mass flow of the fluid circulating covers then an important range of values. In order to give to this study a general character, the diameters of the tubes has been adapted in order to keep a constant value of the flow velocity $\left(1 \mathrm{~m} \cdot \mathrm{s}^{-1}\right.$ here $)$.

- The second one mainly concerns the two heat exchangers that are used to transfer heat between the application and the refrigerant loop.

The frictional pressure drops have been calculated considering the two branches of the loop: at the inlet of the process exchanger (outlet of the evaporator), and at the outlet of the process exchanger. The main reason of that choice is due to the ice slurry properties (mainly viscosity and density) dependence on temperature and ice fraction that can be relatively different at the input and the output.

As mentioned in the introduction, there have been several publications on the subject of pressure drop and flow characteristics of ice water slurries. The carrying fluid in ice slurries can generally be considered as Newtonian, as can slurries themselves if ice mass fraction remains low. Authors agree to say that the ice mass fraction limit separating Newtonian and non Newtonian behaviour is situated about 15/20\%. In general and as in other works, the pressure drop is estimated with the following Darcy-Weissbach [16] relation:

$$
\Delta P=\frac{f \cdot \rho \cdot V^{2} \cdot L}{2 \cdot d}
$$


Where $d$ is the diameter of the tubes, $L$ is the length of the distribution network, $f$ is the dimensionless friction factor, $\rho$ is the density and $V$ is the mean flow velocity. It has to be mentioned that this pressure drop is calculated for the two branches of the loop as working conditions are different (temperature, ice fraction, viscosity, ...).

Friction factor $f$ is a function of Reynolds number. The definition of the Reynolds number that has been adopted in the current investigation is based on the ice slurry properties: The ice slurry viscosity has been calculated using the viscosity proposed by Thomas [17]. For the single phase fluid, usual correlations for a smooth surface have been used to determine the friction factor: Hagen-Poiseuille law $\left(f=64 / \operatorname{Re}_{i s}\right)$ in the case of laminar flow and Blasius law $\left(f=0.3164 / R e_{i s}{ }^{0.25}\right)$ in the turbulent case.

For the ice slurries the friction factor is calculated by a correlation proposed by Snoeck et al. [18]:

$$
f_{d}=f \cdot\left(1+0.119 \cdot X_{v, i s}^{2.151} \cdot R e^{0.2422}+0.02415 \cdot X_{v, i s}^{0.3996} \cdot d^{-0.2845}\right)
$$

Figure 2 shows the relationship between the pressure drop and the ice fraction with various ice slurry mass flow at the conditions experimented by Bédécarrats et al. [9]. An increase in the pressure drop with velocity and the ice fraction is observed. For a given mass flow rate, we note firstly a quite constant or very low increase in the pressure drop with the ice concentration. In this area of low ice slurry concentration, the regime is in fact turbulent mainly because the ice particles contribute to mix the flow. On the other side, the regime becomes laminar as the ice concentration increases. The main consequence of this higher ice fraction is to increase significantly the pressure drops associated to the fluid transport. For the selected flow velocity in the modelled loop (1 $\mathrm{m} \mathrm{s}^{-1}$ ), the change in the flow regime is situated about $20 \%$. A particular point to mention is that in the turbulent area (when the ice fraction remain lower than $15 / 20 \%$ ) 
the order of magnitude of the pressure drops of the flow in the loop tubes is relatively well represented by the monophasic behaviour of the fluid (when the ice fraction equals zero). This property will be used further in order to estimate pressure drops.

Concerning the singularities, especially in the case of heat exchangers, the difficulty mostly lies in the fact that very few studies have been made on the subject.

There have been also few experiments performed on the pressure drop of ice slurry flows in industrial heat exchangers. Studies on ice slurry pressure drops by Bellas et al. [12] for propylene/water in a commercial plate heat exchanger indicate clearly an increase of pressure drop with flow rate and ice fraction. Other research conducted by Shire et al. [13] for $\mathrm{NaCl}$ water slurries in plate and tubular heat exchangers have lead to the same conclusions. The investigated flow rates are ranging from 0.4 to $11 . \mathrm{s}^{-1}$ for Bellas et al. and between 0.5 and $21 . \mathrm{s}^{-1}$ for Shire et al. The corresponding pressure drops reach respectively 0.5 and 2.5 bar. These results are reported in figure 3 . Nevertheless, these results are too much related to the particular heat exchangers under study and can not be used as is.

In order to extend this work and give a more general character to our study (i.e. whatever the kind of heat exchanger), we have investigated another way. It consists in analysing data from common heat exchangers in order to try to extrapolate their behaviour to ice slurries. In most cases, the data that are given by the manufacturers are: the kind of fluid, the mass flow rate and the corresponding pressure drop. If we suppose that a singularity can be represented as an equivalent length of tube, $\Delta P$ can be expressed by eq. (2) and gives:

$$
\Delta P_{\text {nom }}=f_{\text {nom }} \cdot \frac{\rho_{\text {nom }} \cdot V_{\text {nom }}^{2}}{2} \cdot \frac{L}{d}
$$


in the case of the nominal manufacturer's conditions and where $L$ and $d$ refer to an equivalent length and diameter of a virtual tube. With the same assumptions, the pressure drop, when ice slurry is concerned, is supposed as expressed exactly the same:

$\Delta P_{i s}=f_{i s} \cdot \frac{\rho_{i s} \cdot V_{i s}^{2}}{2} \cdot \frac{L}{d}$

As the friction factor is proportional to $R e^{-0.25}$ in turbulent flow regime, that the velocity is related to the mass flow rate through the density, both equations can be combined to obtain finally:

$\Delta P_{i s}=\Delta P_{n o m} \cdot \frac{f_{i s}}{f_{\text {nom }}} \cdot \frac{\rho_{\text {is }} \cdot V_{i s}{ }^{2}}{\rho_{\text {nom }} \cdot V_{\text {nom }}{ }^{2}}=\Delta P_{\text {nom }} \cdot\left(\frac{\mu_{\text {is }}}{\mu_{\text {nom }}}\right)^{0.25} \cdot\left(\frac{\rho_{\text {is }}}{\rho_{\text {nom }}}\right)^{-1} \cdot\left(\frac{\dot{m}_{\text {is }}}{\dot{m}_{\text {nom }}}\right)^{1.75}$

This last expression allows to estimate the pressure drop of an ice slurry flow whatever the conditions if a single point at defined nominal conditions is known. To test these hypotheses and this approach, a comparison has been made with previous abovementioned works $[12,13]$.

Figure 3 shows the variation of ice slurry pressure drop with flow rate, results obtained from these experiments. The pressure drop measured by Bellas et al. are obtained for concentration of $5 \%$ and $20 \%$ propylene/water and those by Shire et al. for concentration of $12.4 \%$ and $25.6 \% \mathrm{NaCl} /$ water. It is interesting to compare these results with those of the model obtained from equation (6). The simulation of the pressure drop fits relatively accurately to the experiments and allows continuing with these hypotheses.

To quantify the pressure drops in manufactured heat exchanger, we need to know the nominal working conditions. Various different plate and shell and tube heat exchangers were investigated (among Alfa Laval and Thermokey models [19, 20] and showed that 
a value of $40 \mathrm{kPa}$ could be considered as the nominal pressure drop for both kinds of exchangers.

If we suppose that the previous part allows determining quite accurately pressure drops, the pumping power can be calculated and is given by:

$\dot{W}_{\text {pump }}=\frac{\left(\Delta P_{\text {in }}+\Delta P_{\text {out }}+\Delta P_{\text {exchanger } 1}+\Delta P_{\text {exchanger } 2}\right) \cdot \dot{m}_{f}}{\rho_{\text {out }} \cdot \eta_{\text {pump }}}$

Where $\Delta P_{\text {exchanger } 1}$ and $\Delta P_{\text {exchanger } 2}$ are the pressure drops of the two exchangers calculated with equation (6). $\eta_{\text {pump }}$ is the efficiency of the pump (ratio between the pumping power and the electrical power consumed by the pump). Both experiments performed in our laboratory and manufacturers brochures agree to consider a value of about $25 \%$ for $\eta_{\text {pump }}$

Before investigating the field that could theoretically be covered by secondary heat transfer fluids, the model itself has been compared to experiments. This has been done thanks to the experimental loop used and described by Bedecarrats et al. [9]. Figure 4 shows in particular the pressure drops measured and calculated by the model in the case of a coaxial heat exchanger for two different flow rates of ice slurry when melting. On an energetic point of view, the electric power consumed by the pump situated on the loop has been measured and calculated according to eq. (7). Results are compared in figure 5 for two different mass flow rates and when ice slurry is being melted. The heat exchanger has been simulated with experimental boundary conditions (temperature and mass flow rate), leading to variations in the results. The conclusion of this work reveals a quite good accuracy of the model concerning pressure drops and the corresponding 
consumed pumping power in the case of ice slurry and validates the model as well as the methodology described above.

\section{Results and discussion}

The binary mixture that has been considered in this study is composed of water and ethanol, mainly because this is a very common couple studied right now. The field of application for secondary refrigerant has been investigated regarding the consumed pumping power versus mass flow rate. The influence of the following parameters has been considered:

- the application power level,

- the application temperature,

- the initial ethanol concentration.

Figure 6 shows the evolution of the temperature and of the ice fraction at the inlet of the heat exchanger with mass flow rate. The application power $\left(\dot{Q}_{a p p}\right)$ considered in our case is $100 \mathrm{~kW}$ and the application temperature $\left(T_{a p p}\right)$ is fixed at $5^{\circ} \mathrm{C}$. The secondary refrigerant output temperature $\left(T_{\text {out }}\right)$ is $5^{\circ} \mathrm{C}$ lower than $T_{a p p}$ and is then $0^{\circ} \mathrm{C}$. These evolutions are calculated as follow: for a given mass flow rate, and as $h_{\text {out }}$ is defined, the input enthalpy is deduced from equation (1). As the ethanol/water initial concentration is known, the temperature and the ice fraction can then be determined from state equations of the ice slurry. Both values are represented in figure $6\left(\mathrm{X}_{\mathrm{ai}}=5 \%\right)$

Depending on the nature of the secondary heat transfer fluid, each evolution can be separated in two areas. On the right (high mass flow), the water/ethanol mixture is liquid only. The important mass flow at constant application power requires a reduced enthalpy variation that can be supplied in our conditions by sensible heat only. As the mass flow decreases, the required enthalpy variation increases and as the ethanol water 
mixture reaches the crystallization temperature (point A), the only way for the solution to compete with the objective is to use latent heat instead of heat sensible. On the left side of the dashed line, the secondary refrigerant is called ice slurry and is composed of water, ethanol and ice crystals. The evolution of the temperature on the beginning of this zone is almost constant and is due to the presence of the ice and of their relatively low proportion in the slurry. On the contrary, for lower values of mass flow, the required amount of ice gets very important, reaching levels generally incompatible with pumping devices. In the same time, the temperature of the ice slurry gets also lower and lower. Such behaviour occurs systematically whatever the ice slurry, but the intensity is directly linked to the temperature and to the ethanol/water initial ratio.

Varying the mass flow has also other consequences, considering the chosen hypotheses. First of all, as the fluid velocity is kept constant $\left(1 \mathrm{~m} \cdot \mathrm{s}^{-1}\right)$, the diameter of the loop tube is systematically adapted. The corresponding pressure drops are then calculated by equation (2) for the loop (a length of $250 \mathrm{~m}$ of tube has been considered here) and by equation 6 , for the heat exchangers. Finally, the pumping power is determined by equation (7), and the results are represented in the figure 7.

In the single phase area, the decrease in the pressure drops is due to their normal dependence to mass flow in this zone. On the left side of point $\mathrm{D}$ (corresponding to the crystallisation of the ice slurry), the fluid is diphasic and the pressure drops still continue to decrease to reach a minimum before growing again for lower mass flows. This particular behaviour is mainly due to the growing dependence of the viscosity with ice concentration. As for pressure drops, the pumping power also passes by a minimum (about $4 \mathrm{~kg} \cdot \mathrm{s}^{-1}$ in our case). This demonstrates that an optimum, from an energetic point of view, exists when pumping ice slurries in such kinds of loops. 
Figure 8 gives the evolution of the pumping power with mass flow rate for different values of application power. The main important result comparing single (dashed line) and two phases (solid line) is that the lower pumping power is systematically in the diphasic zone. The area of study of the flow has been restricted to ice fraction lower than $30 \%$ and explains why the curves do not begin all with the same flow rate value. The second point to mention is that the evolution of the pumping power is not monotonous and passes systematically, for each application power, by a minimum (points in the figure) corresponding to a particular mass flow. Decreasing the mass flow of the ice slurry is desirable because it leads to a significant reduction in pumping power unless the influence of the viscosity remains weak. Figure 9 shows that a minimum also appears when other conditions of temperature and initial concentration are investigated.

\section{Conclusion}

The main aim of this project was to develop a model providing engineering information facilitating the design of efficient ice slurry systems. In particular, the objective is to improve the operations of distribution and use of the cold in the association of a refrigerating generator and a loop of secondary refrigerant from an energetic point of view. In a first part, the presented model enables us to estimate pressure drops in fluid loops. Compared to the results obtained from previous studies, the model turns out to be quite accurate to calculate pressure drops in the case of heat exchangers of different technologies. The pumping power required for the secondary heat transfer fluid to circulate is then also estimated by the model and also validated in the case of our experimental loop. 
Then, these results enable us to extrapolate the conclusion in order to estimate the energetic benefit in using ice slurry. Considering different application powers and temperatures as well as the initial concentration of a water/ethanol mixture, a minimum in the consumed power is observed systematically. The second point that has been pointed out by this work is that the position of that minimum is always when the fluid is diphasic, i.e. when ice slurry is concerned.

Then, the use of ice slurry can lead to much lower flow rates and pumping power compared to single-phase secondary distribution systems. Nevertheless, the pump is not the only consuming power device in such installations and the integration of the refrigerant loop will be the next step to complete the model and access the global consumption of energy of such installations.

\section{Acknowledgement}

This study was supported by the Joint Committee Inter-University Franco-Morocco within the framework of the Integrated Action n ${ }^{\circ}$ MA/06/152

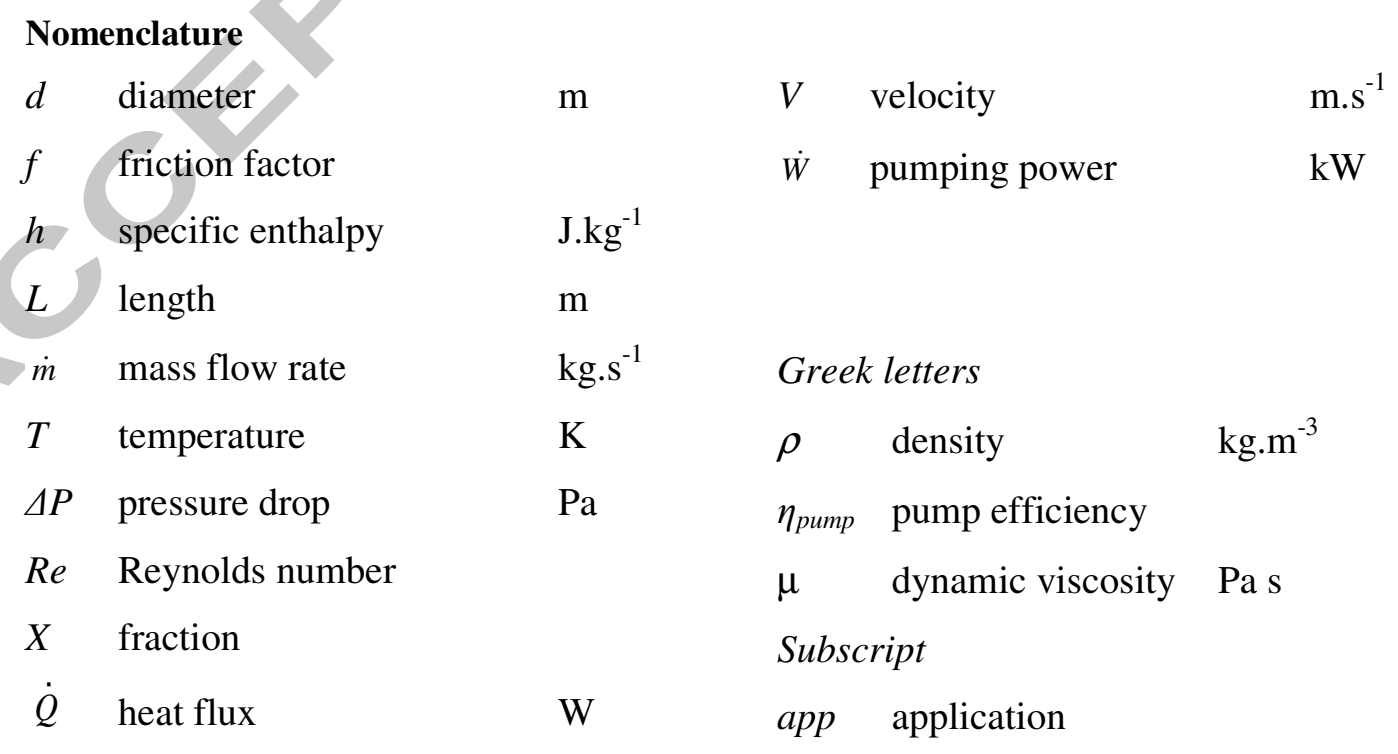




$\begin{array}{llll}\text { in,out } & \text { inlet, outlet } & \text { is } & \text { ice slurry } \\ e q & \text { equivalent } & \text { ai } & \text { alcohol initial } \\ d & \text { diphasic } & \text { nom } & \text { nominal } \\ f & \text { fluid } & \text { v } & \text { volumetric }\end{array}$

\section{References}

[1] M. Kauffeld, M. Kawaji, P. Egolf, Handbooks on Ice Slurries Fundamentals an Engineering IIF/IIR (2005).

[2] P. Egolf, M. Kauffeld, From physical properties of ice slurries to industrial. Int. J. Refrigeration 28 (2005), 4-12.

[3] I. Bellas and S.A. Tassou, Present and future applications of ice slurries, Int J Refrigeration 28 (2005), 115-121.

[4] V. Ayel, O. Lottin, H. Peerhossaini, Rheology, flow behaviour and heat transfer of ice slurries: a review of the state of the art. Int. J. Refrigeration 26 (2003), 95107.

[5] B. Niezgoda-Zelasko, Heat transfer of ice slurry flows in tubes. Int. J. Refrigeration 29 (2006), 437-450.

[6] B. Niezgoda-Zelasko, B. Zalewski, Momentum transfer of ice slurry flows in tubes, experimental investigations. Int. J. Refrigeration 29 (2006), 418-428

[7] M. Grozdek, R. Khodabandeh, P. Lundqvist, B. Palm, A. Melinder, Experimental investigation of ice slurry heat transfer in horizontal tube, Int. J. of Refrigeration (2009), doi: 10.1016/j.ijrefrig.2009.01.014 
[8] M. Grozdek, R. Khodabandeh, P. Lundqvist, 2009. Experimental investigation of ice slurry flow pressure drop in horizontal tubes, Experimental Thermal and Fluid Science 33 (2009), 357-370

[9] J.-P. Bédécarrats, F. Strub and C. Peuvrel, Thermal and hydrodynamic considerations of ice slurry in heat exchangers, International Journal of Refrigeration (2009), doi:10.1016/j.ijrefrig.2009.04.002

[10] E. Nørgaard, T.A. Sørensen, T.M. Hansen, M. Kauffeld. Performance of components of ice slurry systems: pumps, plate heat exchangers, and fittings. International Journal of Refrigeration 28 (2005) 83-91

[11] E.N. Jensen, K.G. Christensen, T.M. Hansen, P. Schneider, M. Kauffeld, Pressure drop and heat transfer with ice slurry, in: Final Proceedings of the IIR-Gustav Lorentzen Conference on Natural Working Fluids at Purdue, Ray W. Herric Laboratories, West Lafayette, IN, 25-28 July 2000, p. 572-580.

[12] J. Bellas, I. Chaer, S.A. Tassou, Heat transfer and pressure drop of ice slurries in plate heat exchangers. Appl. Therm. Eng. 22(2002) 721-732.

[13] G.S.F. Shire, G.L. Quarini, T.S. Evans, Pressure drop of flowing ice slurries in industrial heat exchangers, Applied Thermal Engineering 29 (2009) 1500-1506

[14] P. Haberschill, A. Lallemand, Etude comparative de l'intérêt de l'emploi des fluides frigoporteurs monophasiques et diphasiques pour la climatisation, in: Final Proceedings of COFRET'04, Nancy-France

[15] M. A. Ben Lakhdar, Comportement thermo-hydraulique d'un fluide frigoporteur diphasique le coulis de glace. Etudes théorique et expérimentale, $\mathrm{PhD}$ Thesis (in french) INSA Lyon, 18 Novembre (1998). 
[16] F. M. White. Fluid Mechanics. $4^{\text {th }}$ edition. McGraw-Hill International Editions. ISBN 0-07-116848-6.

[17] D.G.Thomas, Transport characteristics of suspension: VIII. A note on the viscosity of Newtonian suspension of uniform spherical particles, Journal of Colloïd Science (1965) 267-277.

[18] C.W. Snoeck, S. Walosik, R.P. Gupta, Ice slurry transport for district cooling networks. Slurry handling and pipeline. Transport-hydrotransport 12 Snoeck C.ed, Mechanical Engineering Publication Ltd, London 1993 pp.511-524.

[19] http://www.alfalaval.com/

[20] http://www.thermokey.com/

\section{Figure captions}

Figure 1: Cold distribution network using secondary refrigerant fluid.

Figure 2: Variation of pressure drop with ice fraction for different flow velocities. Results from Bédécarrats [9].

Figure 3: Variation of pressure drop with flow rate at different ice fractions and different heat exchangers from $[12,13]$. Comparison between experiments (points) and our model (solid lines).

Figure 4: Comparison of the experimental (points) and simulated (solid lines) evolutions of pressure drop in our heat exchanger [9] for two different mass flow rates of ice slurry.

Figure 5: Comparison of the experimental (points) and simulated (solid lines) evolutions of the pumping power for our loop [9] for two different mass flow rates of ice slurry. Figure 6: Evolution of the temperature and mass ice fraction at the inlet of the heat exchanger with mass flow. 
Figure 7: Evolution of the pumping power and pressure drop with mass flow rate.

Figure 8: Pumping power dependence with mass flow rate and different application powers for a $0^{\circ} \mathrm{C}$ application temperature and an initial ethanol concentration of $5 \%$ Figure 9: Pumping power dependence with mass flow rate and different application powers for $\mathrm{a}-5^{\circ} \mathrm{C}$ application temperature and an initial ethanol concentration of $15 \%$ 


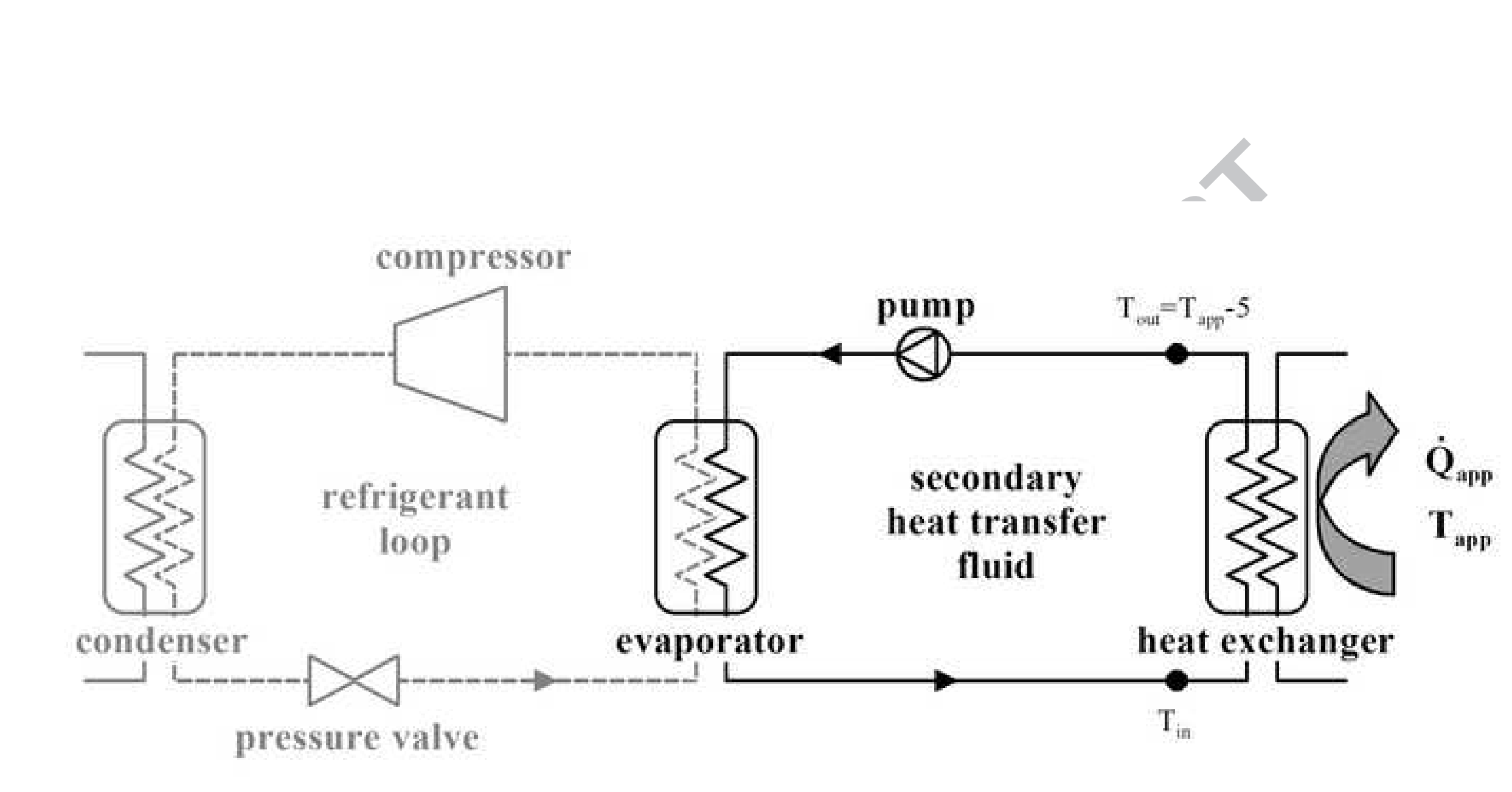




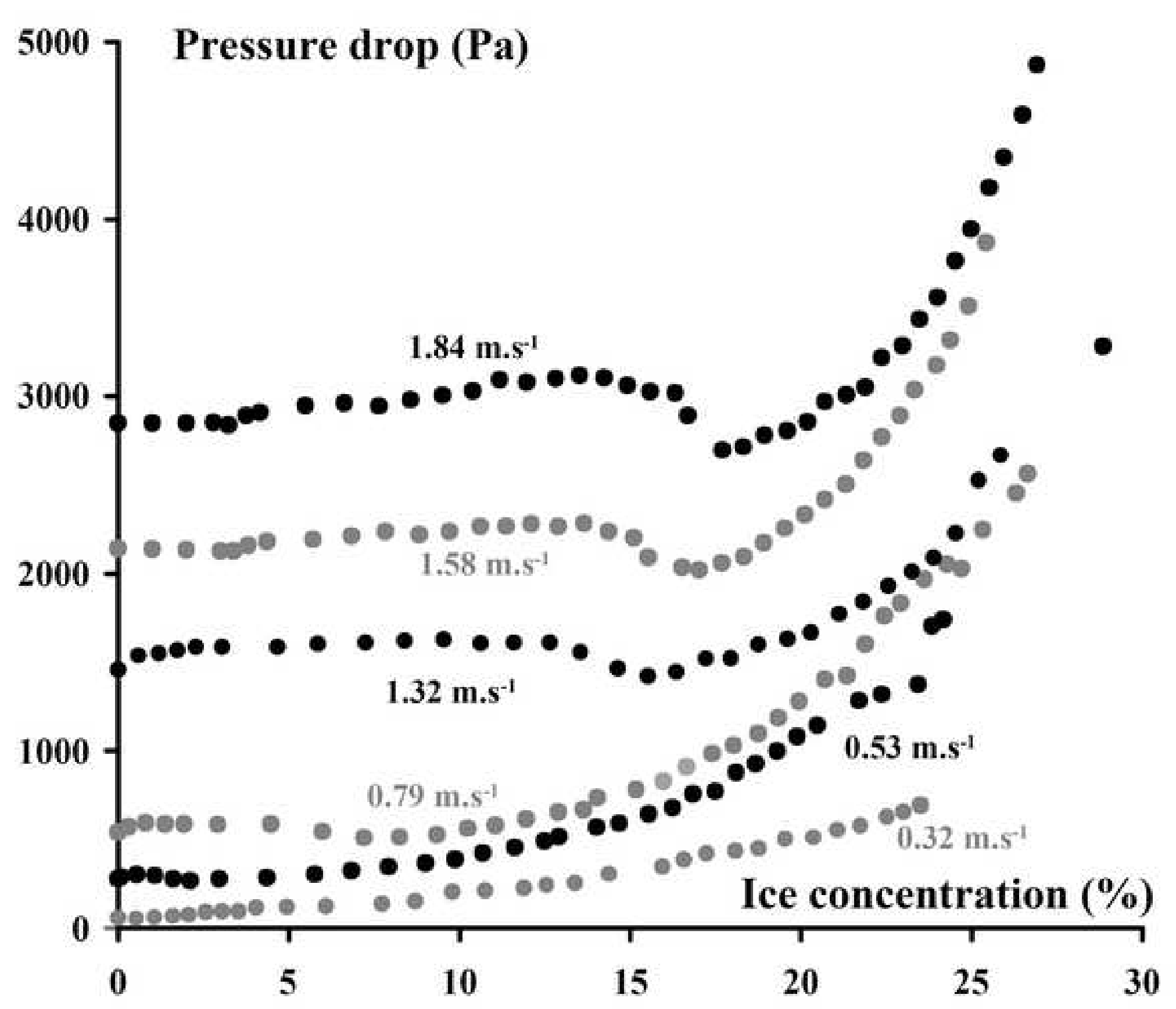




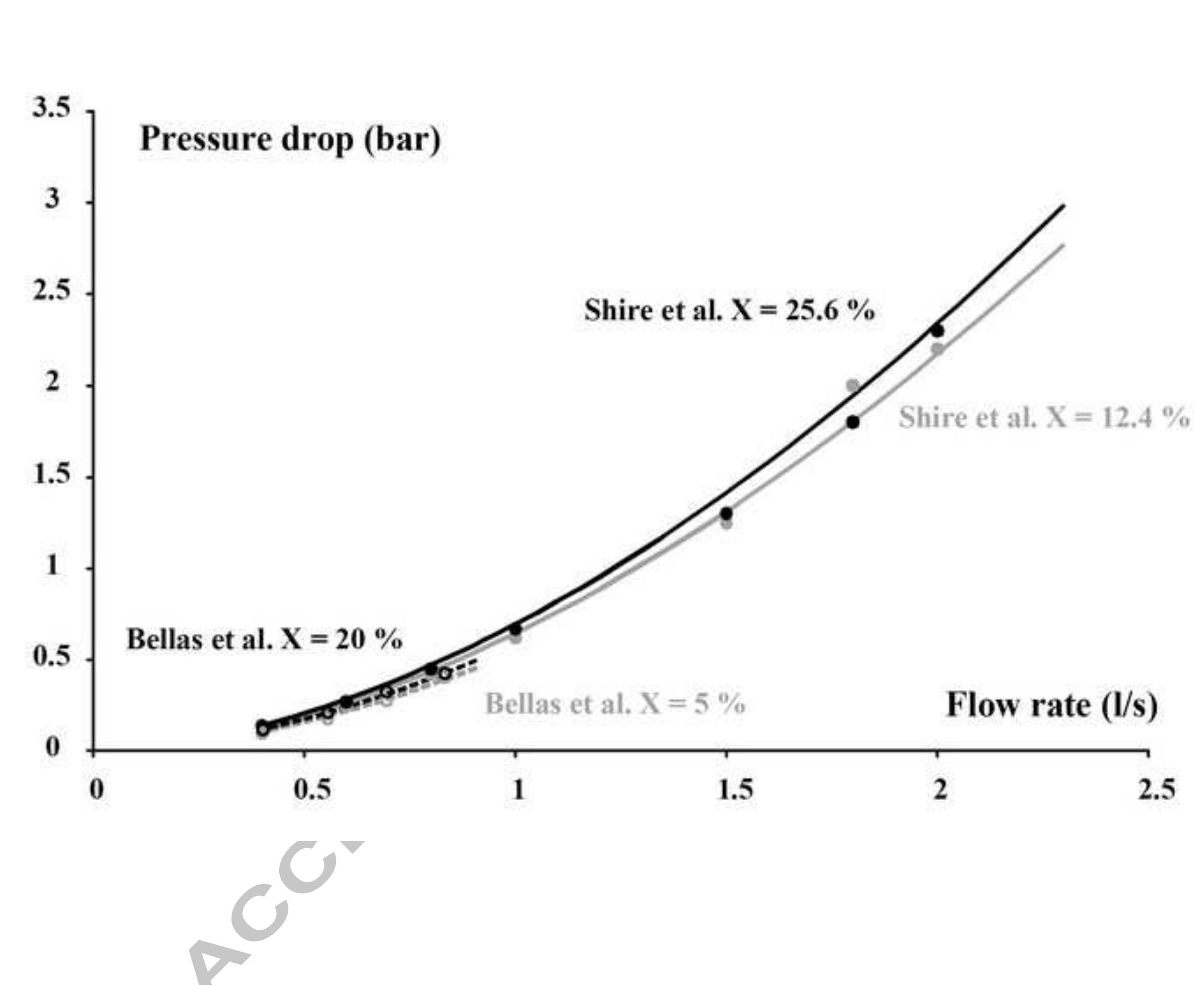

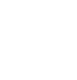




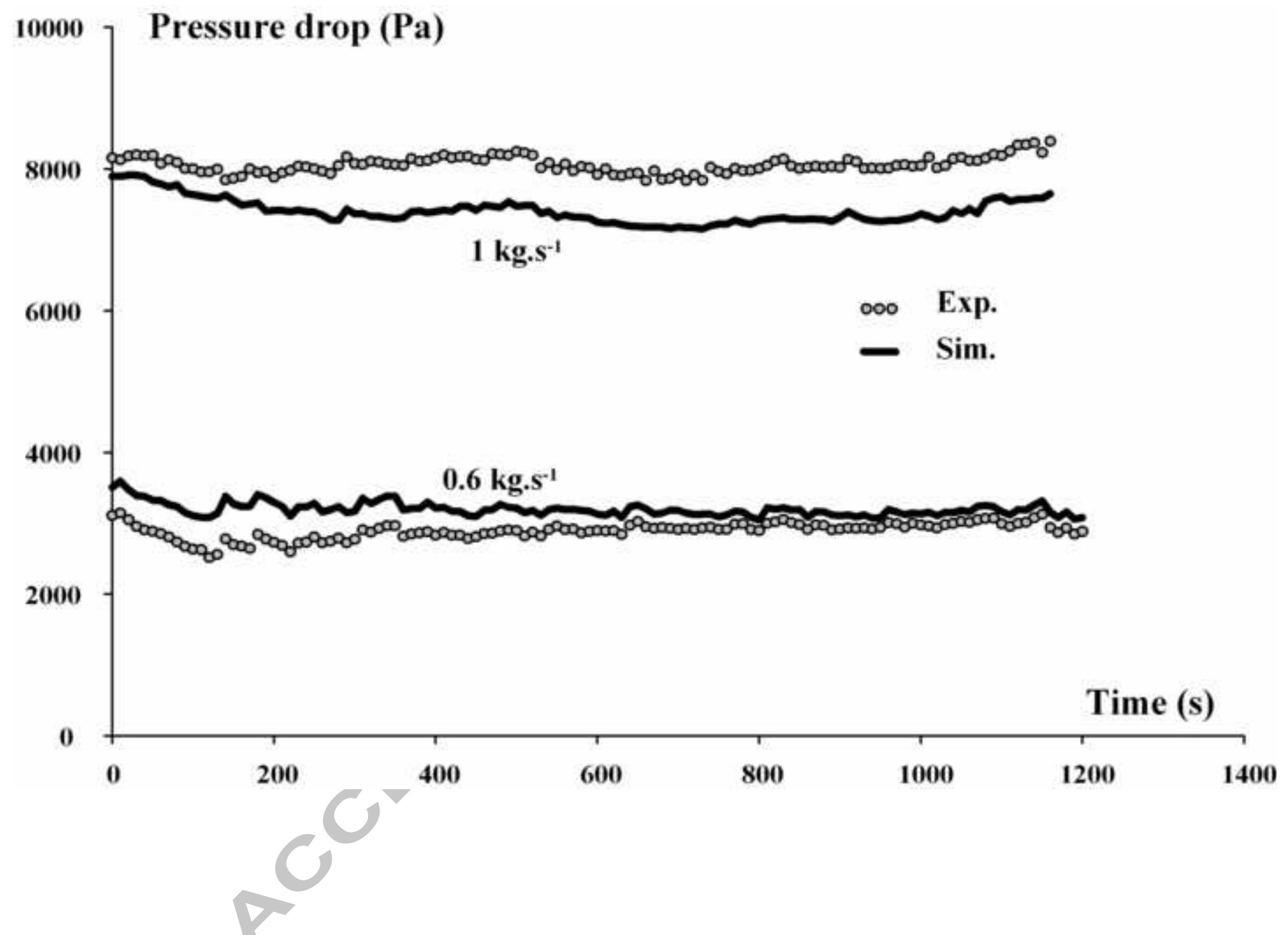

- Sim.

Time (s)

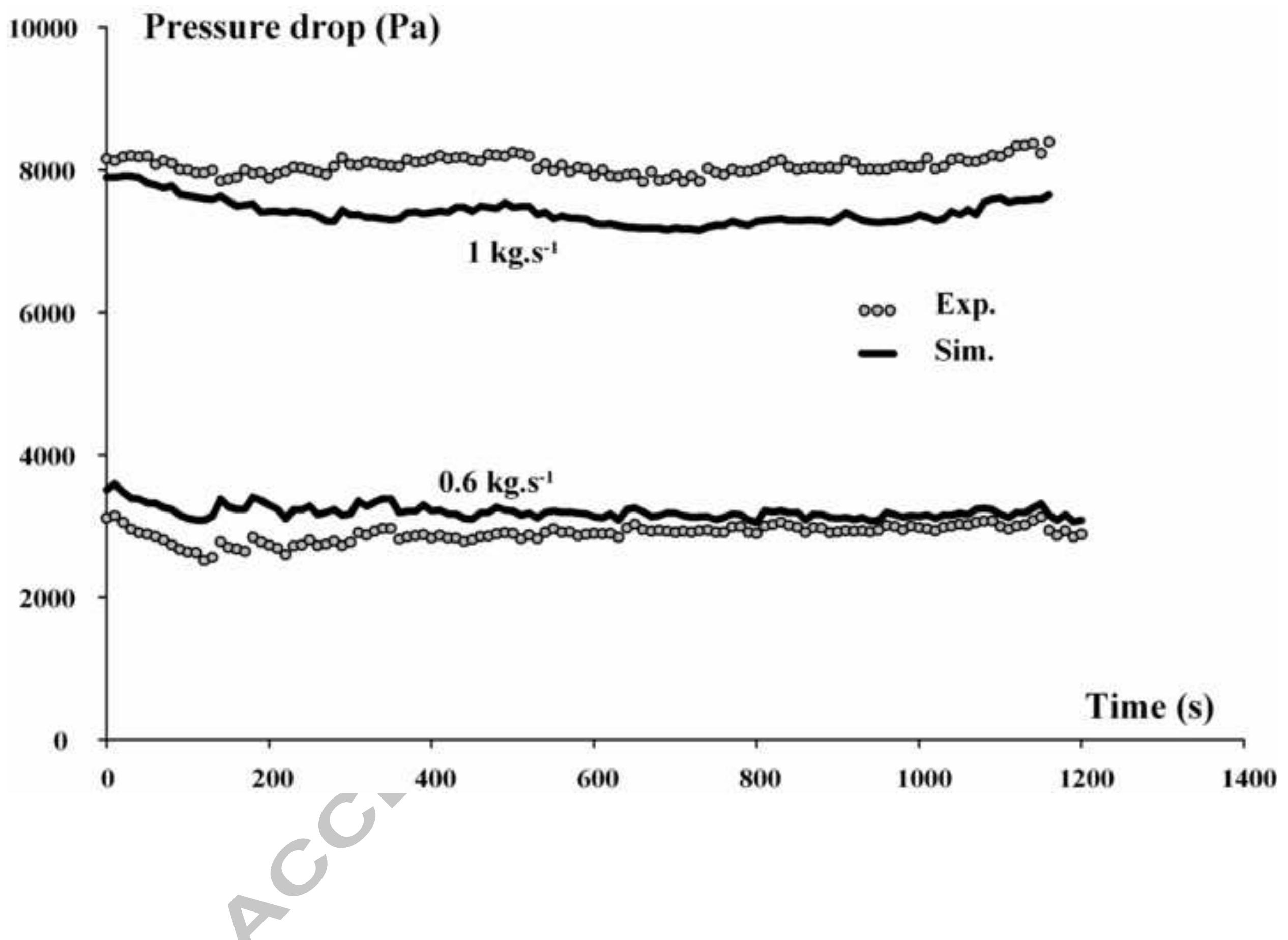

40 


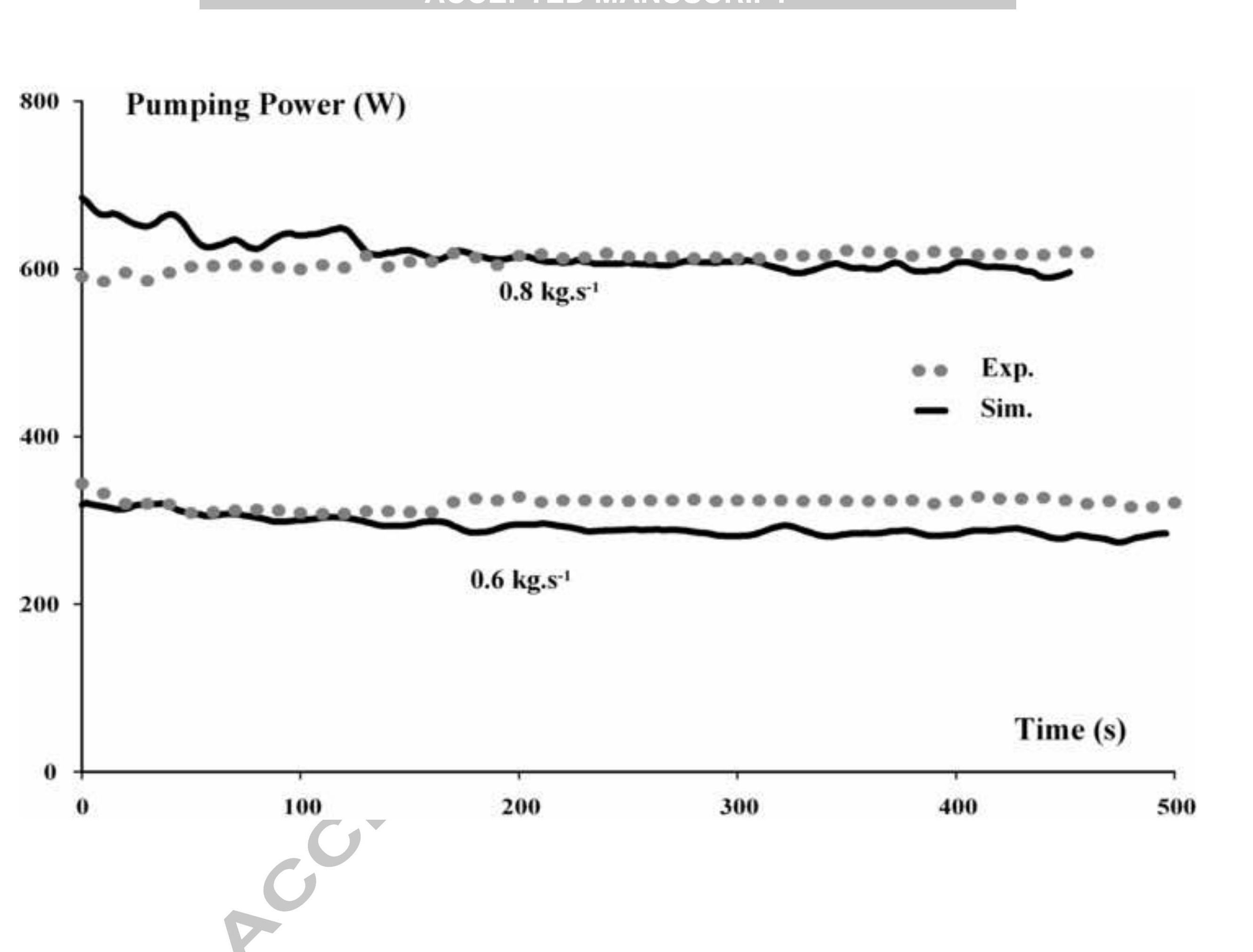

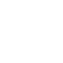

.

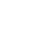

.

.

. 


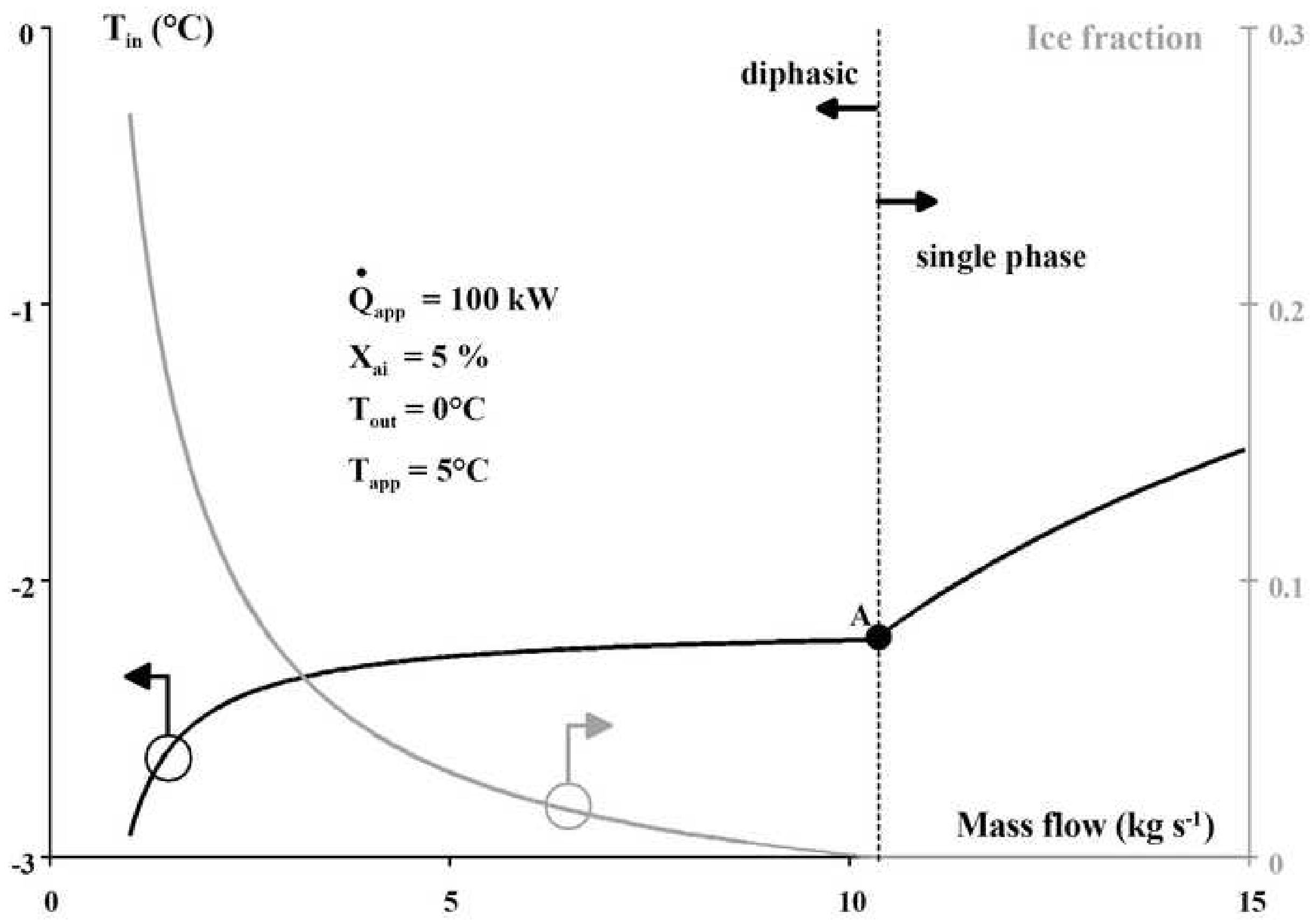

$\dot{\mathrm{Q}}_{\mathrm{app}}=100 \mathrm{~kW}$

$\mathrm{X}_{\mathrm{ai}}=\mathbf{5} \%$

$\mathrm{T}_{\text {out }}=0^{\circ} \mathrm{C}$

$\mathrm{T}_{\text {app }}=\mathbf{5}^{\circ} \mathrm{C}$
Mass flow $\left(\mathrm{kg} \mathrm{s}^{-1}\right)$ 


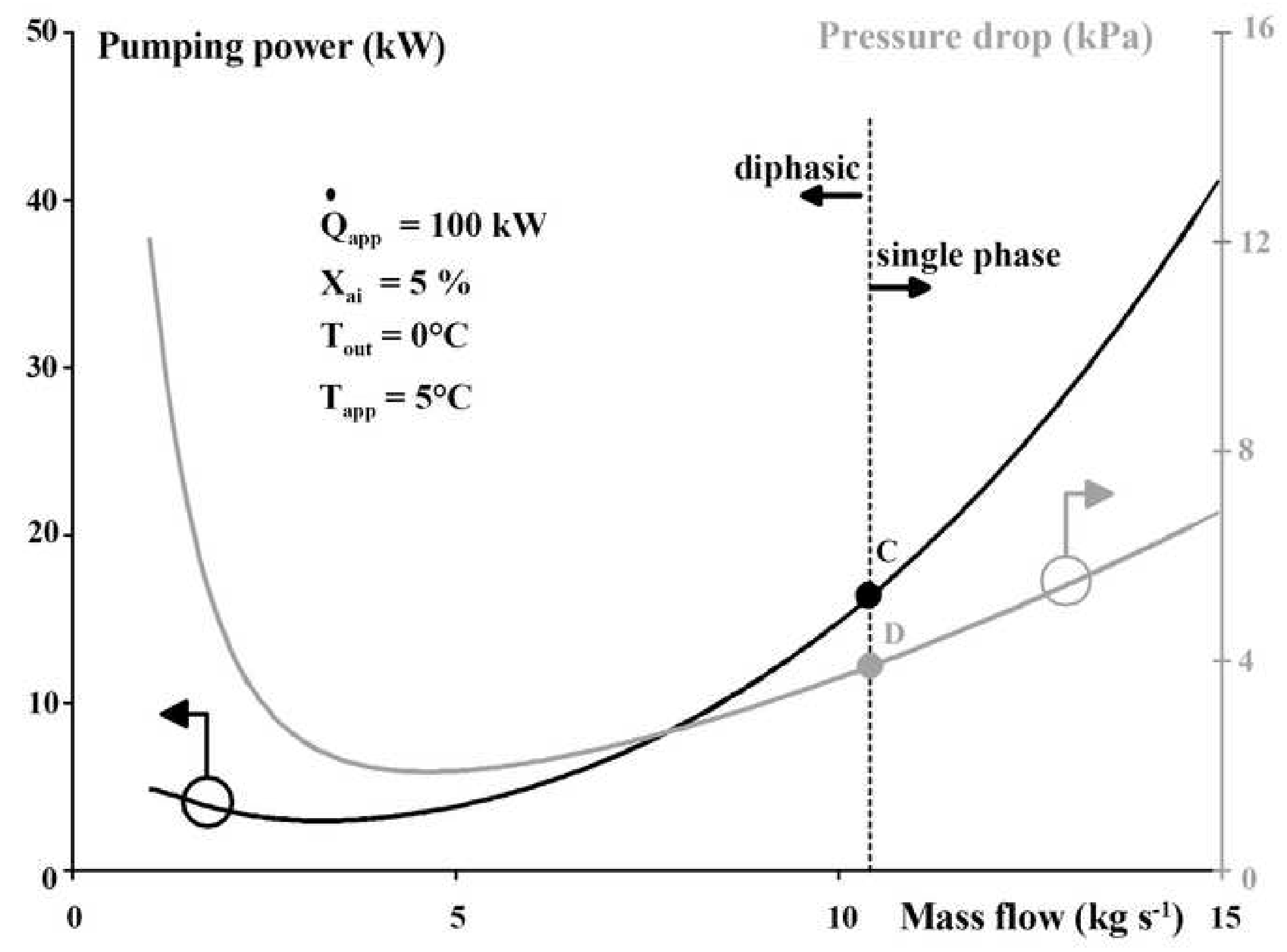




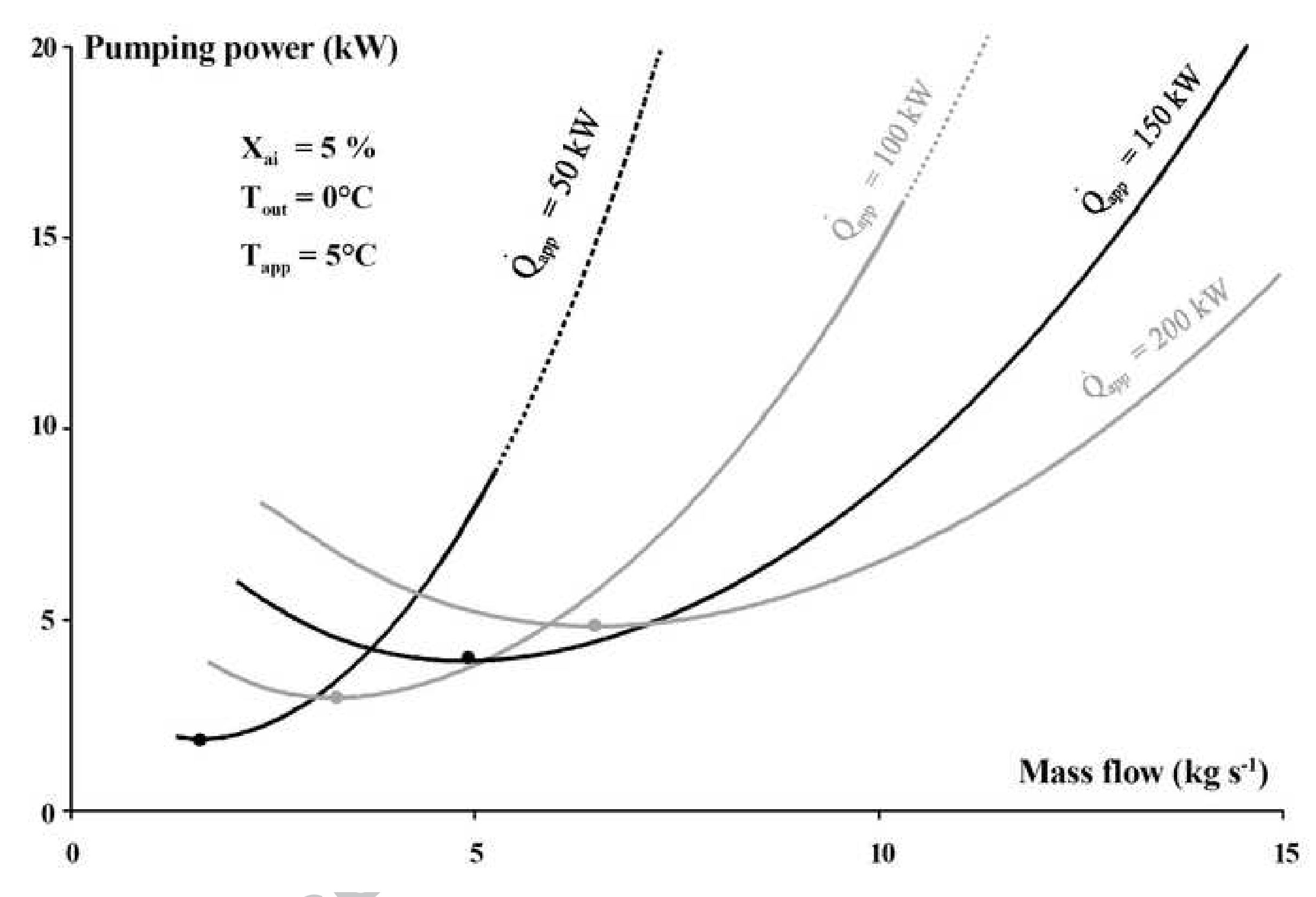

\section{5}




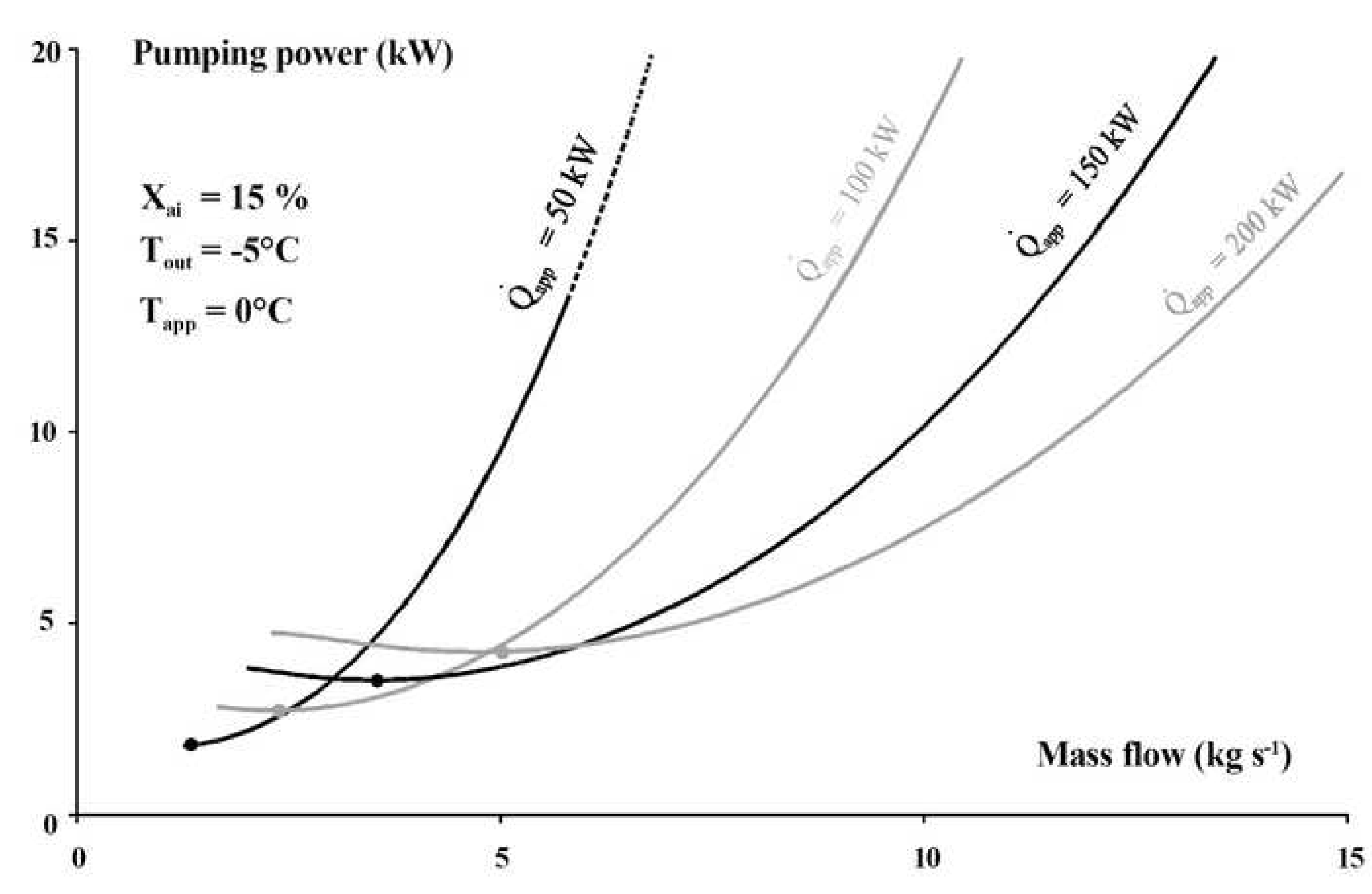
5 